\title{
BMJ
}

\section{Objectively measured physical capability levels and mortality: systematic review and meta-analysis}

\author{
Rachel Cooper, MRC career development fellow Diana Kuh, professor of life course epidemiology and MRC \\ unit director Rebecca Hardy, MRC programme leader, Mortality Review Group on behalf of the FALCon and \\ HALCyon study teams
}

MRC Unit for Lifelong Health and Ageing and Division of Population Health, University College London, London WC1B 5JU

Correspondence to: $\mathrm{R}$ Cooper r.cooper@nshd.mrc.ac.uk

Cite this as: $B M J$ 2010;341:C4467 doi:10.1136/bmi.c4467

\section{ABSTRACT}

Objective To do a quantitative systematic review, including published and unpublished data, examining the associations between individual objective measures of physical capability (grip strength, walking speed, chair rising, and standing balance times) and mortality in community dwelling populations.

Design Systematic review and meta-analysis.

Data sources Relevant studies published by May 2009 identified through literature searches using Embase (from 1980) and Medline (from 1950) and manual searching of reference lists; unpublished results were obtained from study investigators.

Study selection Eligible observational studies were those done in community dwelling people of any age that examined the association of at least one of the specified measures of physical capability (grip strength, walking speed, chair rises, or standing balance) with mortality. Data synthesis Effect estimates obtained were pooled by using random effects meta-analysis models with heterogeneity between studies investigated.

Results Although heterogeneity was detected, consistent evidence was found of associations between all four measures of physical capability and mortality; those people who performed less well in these tests were found to be at higher risk of all cause mortality. For example, the summary hazard ratio for mortality comparing the weakest with the strongest quarter of grip strength (14 studies, 53476 participants) was 1.67 (95\% confidence interval 1.45 to 1.93 ) after adjustment for age, sex, and body size $\left(I^{2}=84.0 \%\right.$, 95\% confidence interval $74 \%$ to $90 \%$; P from Q statistic $<0.001$ ). The summary hazard ratio for mortality comparing the slowest with the fastest quarter of walking speed (five studies, 14692 participants) was 2.87 (2.22 to 3.72$)\left(I^{2}=25.2 \%, 0 \%\right.$ to $70 \% ; \mathrm{P}=0.25)$ after similar adjustments. Whereas studies of the associations of walking speed, chair rising, and standing balance with mortality have only been done in older populations (average age over 70 years), the association of grip strength with mortality was also found in younger populations (five studies had an average age under 60 years).

Conclusions Objective measures of physical capability are predictors of all cause mortality in older community dwelling populations. Such measures may therefore provide useful tools for identifying older people at higher risk of death.

\section{INTRODUCTION}

Physical capability, a term used to describe a person's ability to do the physical tasks of everyday living, ${ }^{1}$ can be assessed by self report or objectively by using tests such as grip strength, walking speed, chair rising, and standing balance. Growing evidence from single studies suggests that these objective measures of physical capability are also useful markers of current and future health. As a result, interest is increasing in these tests and their potential use as simple screening tools in the general population to identify people who may benefit from targeted intervention (such as strength training) or among patient groups to assess response to treatment. $^{23}$

No systematic review of the literature has been done to examine the associations of walking speed, standing balance, or chair rises with mortality. Existing reviews of grip strength have not done meta-analyses of results or investigated heterogeneity between studies. ${ }^{45}$ Whether associations are restricted to older populations with comorbidities that adversely affect physical capability and increase risk of death or are also found when physical capability is assessed in other populations, including those that are younger, thus remains unclear.

We did a systematic review to test the hypothesis that lower levels of physical capability in community dwelling populations would be associated with higher subsequent risk of poor health and mortality. In this paper, we focus on all cause mortality as the end point. We aimed to do meta-analyses of results acquired from published studies and through contact with authors of studies to obtain estimates of the size of the associations of grip strength, walking speed, chair rise time, and standing balance performance with mortality. We also investigated whether these associations varied by sex, age at baseline, length of follow-up, or country of study. 


\section{METHODS}

We did a systematic review of existing literature, following the meta-analysis of observational studies in epidemiology (MOOSE) guidelines and the PRISMA statement. ${ }^{67}$

\section{Search strategy and selection criteria}

Eligible observational studies were those done in people of any age living in the community that examined the association of at least one of the specified measures of physical capability (grip strength, walking speed, chair rises, or standing balance) with mortality (full review protocol available on request). We excluded studies of patient groups.

$\mathrm{RC}$ searched the electronic databases Medline (from 1950) and Embase (from 1980) to May 2009 by using free text search terms (see web appendix) with no restrictions by language. The initial search included search terms for other selected health outcomes, but those results are reported elsewhere. ${ }^{8}$

Figure 1 summarises the initial identification of studies. Combining the results of the electronic searches and removing duplicate records left abstracts of 2270 unique records to be screened independently by two

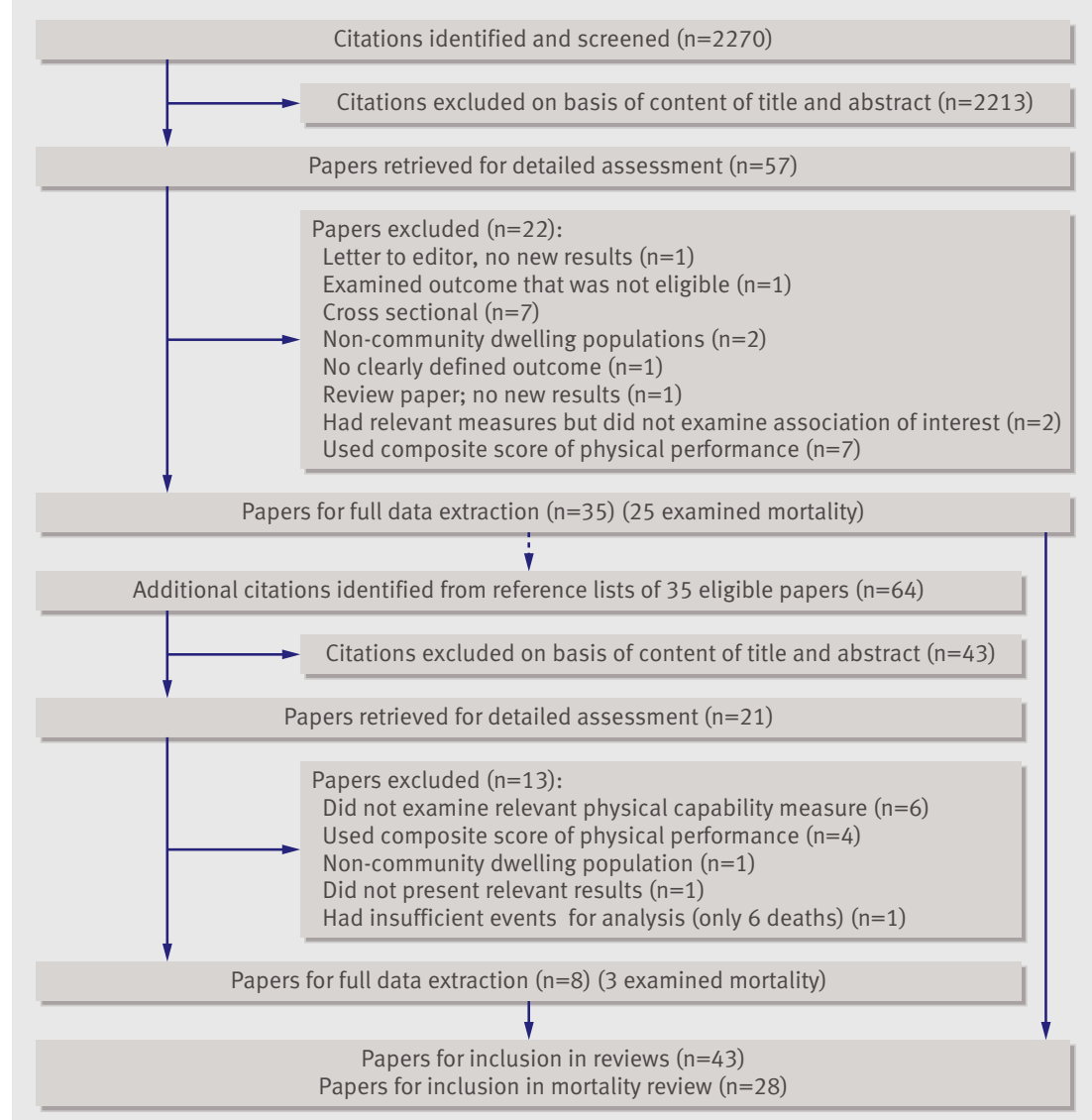

Fig 1 1 Flow diagram for identification of published studies. Includes identification of studies for additional review of other health outcomes, reported elsewhere ${ }^{8}$ authors (RC and RH). Examining the full text of 57 potentially eligible papers led to the identification of 25 papers with mortality as an outcome that were eligible for inclusion. ${ }^{9-33} \mathrm{RC}$ and $\mathrm{RH}$ independently extracted the following data from these papers by using a standardised form: relevant published results; study population, selection, and baseline characteristics; study exclusion criteria; details of methods for ascertaining physical capability and mortality; and adjustments made for potential confounders. RC and RH made an assessment of each study's quality on the basis of a modified version of the Newcastle-Ottawa quality assessment scale ${ }^{34}$; however, no studies were excluded on the basis of this assessment. The same two authors independently searched the reference lists of all eligible papers and identified a further 64 abstracts to screen, resulting in the identification of a further three papers that were eligible for inclusion. ${ }^{35-37}$ Disagreements about the eligibility of a study or differences between the two sets of information extracted were resolved through discussion.

\section{Contact with study authors}

We contacted the corresponding authors of 23 of the 28 eligible papers and asked them to complete standardised results tables (copies available on request) (fig 2). Of the five papers for which authors were not contacted, we could not find up to date contact details for two,${ }^{1522}$ the third had used the same study population as other authors being contacted but had shorter follow-up, ${ }^{35}$ and a further two were not identified until after the deadline for contacting authors. ${ }^{2728}$

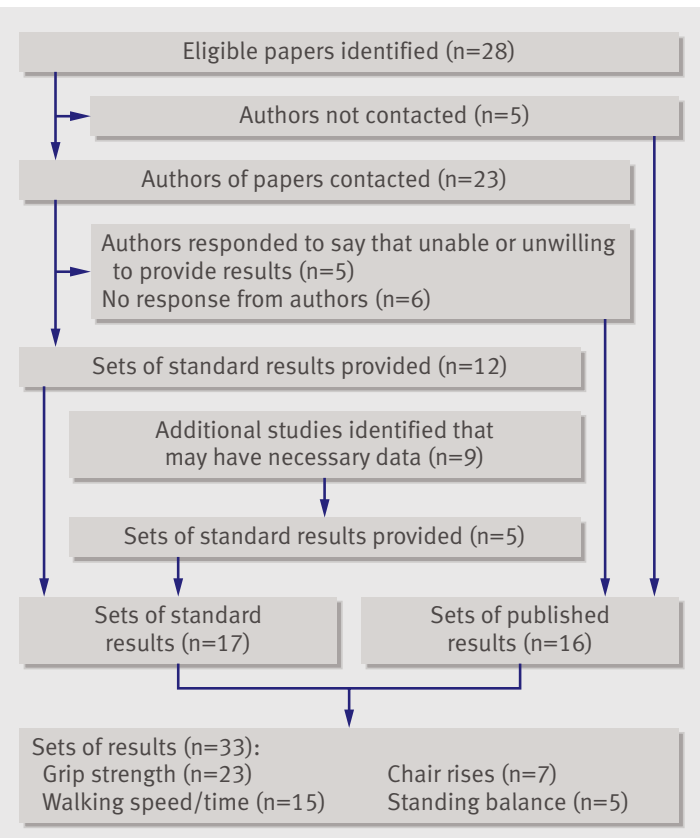

Fig 2 Flow diagram showing contact with authors and ascertainment of results for inclusion in review 
We asked authors to analyse the associations between each individual measure of physical capability available and all cause mortality, using survival analyses where possible, on men and women separately and also combined. We requested three separate sets of models: unadjusted, age adjusted, and age and body size (height and weight or body mass index) adjusted, with the addition of sex in the second and third models when run on men and women combined. For all capability measures, we asked authors for a comparison of sex specific quarters with the best performing group used as the reference category. For grip strength, we also asked authors to provide estimates for a one unit increase (we did not request estimates for a one unit increase for the other three capability measures because of the variation in the units of measurement). After sending one reminder, we received responses to 17 of the 23 requests and 12 standard sets of results were provided; the other five responses informed us of the author's inability to provide results (fig 2).

We also contacted the corresponding authors of a further nine papers identified during screening of abstracts as having potentially relevant data but who had not published results from tests of the association between physical capability measures and mortality. ${ }^{38-46}$ This resulted in five sets of additional results for inclusion (fig 2).

\section{Statistical methods}

We based analyses on the standard requested results if they had been provided, using published results when requested results were not available. If necessary, we converted effect estimates for a per unit change in grip strength to a per $1 \mathrm{~kg}$ increase in grip strength.

When more than three sets of comparable results were available, we did random effects metaanalyses. ${ }^{47} \mathrm{We}$ ran these analyses first on the sex and age adjusted estimates and then with additional adjustment for body size. We then added estimates from models with alternative adjustments into the meta-analysis for those studies $(n=4)$ for which standard adjustments were not available; this was the case only for analyses of per unit change in grip strength. In all these initial analyses, we used the combined sex adjusted effects for men and women when they were available and the sex specific estimates only when they were not. We used $\mathrm{I}^{2}$ and $Q$ statistics to investigate between study heterogeneity. ${ }^{4849}$ We examined potential sources of heterogeneity, including sex, mean age of study participants, length of follow-up, and region of study (as pre-specified in the protocol), by stratifying meta-analyses by each of these factors and by doing meta-regression analyses when we had more than 10 sets of results. ${ }^{50}$ We used permutation tests to obtain $\mathrm{P}$ values corrected for multiple testing. ${ }^{51} \mathrm{We}$ also re-ran the main meta-analyses with each study removed in turn to check that no one study was explaining any heterogeneity found. We examined funnel plots to assess publication bias. ${ }^{52} \mathrm{We}$ also used the tests proposed by Egger and colleagues and Begg and Mazumdar for this purpose..$^{5354}$

\section{RESULTS}

Study characteristics

We considered most of the studies to be of good quality (web table A). This was partly because physical capability was usually measured by trained professionals either in a home or clinic setting and mortality was ascertained by methods considered to be reliable, such as record linkage which usually results in little loss to follow-up.

Most studies were done in older populations (web table A and tables 1 and 3). None of the studies that reported on associations of walking speed, chair rises, or standing balance with mortality was in a population with an average age under 61 years, and in most the average age was over 70 years. Studies of grip strength and mortality covered a wider range of ages, and five had an average age of under 60 years.

Although similar numbers of studies of grip strength and mortality had short ( $\leq 5$ years), intermediate (6-20 years), and longer ( $>20$ years) follow-up, followup in studies of walking speed has usually been five years or less (no studies reported follow-up of more than 10 years), and in studies of chair rises follow-up has usually been between six and 10 years (tables 1 and 3). Most studies have been done in the United States, but studies have also been done across Europe and in Japan, Hong Kong, and Australia.

Although we did not assess the protocols for measuring physical capability used in different studies as part of our review, we did record that a range of different instruments have been used to measure grip strength. Most of these instruments are different types of handheld dynamometer, and authors tend to use either the maximum value recorded or the average achieved over a fixed number of trials in their models. Walking speed has been measured in different studies over distances of 4, 6, and 10 metres and 8 and 16 feet. Of the studies of chair rises identified, all had asked participants to do five rises.

We had a total of 33 sets of results for consideration in this review, consisting of 16 sets of published results and 17 sets of results in a specified format (web table A). Grip strength was the most frequently examined measure in the published literature; 19 of the 28 papers identified reported on the association of this measure with mortality. Fourteen papers reported results for the association between walking speed or time and mortality, four reported on standing balance, and three reported on chair rises. Of the five additional studies included after contact with authors, four provided results for grip strength, two for walking speed, four for chair rises, and one for standing balance.

\section{Assessment of publication bias}

Examination of funnel plots suggested no clear evidence of publication bias. This was confirmed by the results from tests proposed by Egger and colleagues and Begg and Mazumdar, ${ }^{534}$ which produced $\mathrm{P}$ values of 0.28 or greater. 
Table 1| Results from stratified meta-analyses of age, sex, and body size adjusted hazard ratios of associations of grip strength with all cause mortality

\begin{tabular}{|c|c|c|c|c|c|c|c|c|}
\hline \multirow[b]{2}{*}{ Stratification } & \multicolumn{4}{|c|}{ Per $1 \mathrm{~kg}$ increase } & \multicolumn{4}{|c|}{ Lowest $v$ highest quarter comparison } \\
\hline & No* & $\begin{array}{l}\text { Summary hazard } \\
\text { ratio }(95 \% \mathrm{Cl})\end{array}$ & $12(\%)$ & P value $\ddagger$ & No* & $\begin{array}{l}\text { Summary hazard } \\
\text { ratio }(95 \% \mathrm{Cl})\end{array}$ & $12(\%)$ & P value $\neq$ \\
\hline None & 14 & 0.97 (0.97 to 0.98$)$ & 89.5 & $<0.01$ & 14 & $1.67(1.45$ to 1.93$)$ & 84.0 & $<0.01$ \\
\hline \multicolumn{9}{|c|}{$\begin{array}{l}\text { Mean age at baseline } \\
\text { (years): }\end{array}$} \\
\hline$\leq 60$ & 3 & 0.97 (0.97 to 0.98) & 13.7 & 0.31 & 4 & $1.43(1.07$ to 1.91$)$ & 86.4 & $<0.01$ \\
\hline $61-70$ & 4 & 0.97 (0.94 to 1.01$)$ & 90.7 & $<0.01$ & 2 & 1.81 (0.73 to 4.49$)$ & 68.0 & 0.08 \\
\hline$>70$ & 7 & 0.97 (0.96 to 0.98) & 90.5 & $<0.01$ & 8 & 1.80 (1.48 to 2.18$)$ & 81.9 & $<0.01$ \\
\hline \multicolumn{9}{|c|}{ Length of follow-up (years): } \\
\hline$\leq 5$ & 5 & 0.96 (0.95 to 0.97) & 39.7 & 0.16 & 5 & $2.16(1.70$ to 2.75$)$ & 31.9 & 0.21 \\
\hline $6-10$ & 4 & 0.98 (0.95 to 1.00$)$ & 95.8 & $<0.01$ & 2 & 2.26 (1.88 to 2.72$)$ & 0 & 0.70 \\
\hline $11-20$ & 2 & 0.97 (0.97 to 0.98) & 0 & 0.34 & 2 & $1.43(1.33$ to 1.54$)$ & 0 & 0.91 \\
\hline$>20$ & 3 & 0.98 (0.97 to 0.99) & 90.7 & $<0.01$ & 5 & 1.39 (1.15 to 1.70$)$ & 81.9 & $<0.01$ \\
\hline \multicolumn{9}{|l|}{ Region of study: } \\
\hline North America & 8 & 0.97 (0.96 to 0.97) & 60.4 & 0.01 & 7 & 1.64 (1.35 to 2.01$)$ & 89.1 & $<0.01$ \\
\hline Japan & 4 & 0.99 (0.97 to 1.00$)$ & 87.1 & $<0.01$ & 1 & 1.98 (1.64 to 2.40$)$ & - & - \\
\hline Other & 2 & 0.98 (0.94 to 1.01$)$ & 72.3 & 0.06 & 6 & 1.64 (1.31 to 2.06$)$ & 59.1 & 0.03 \\
\hline \multicolumn{9}{|l|}{ Sex§: } \\
\hline Male & 10 & 0.97 (0.96 to 0.98$)$ & 91.6 & $<0.01$ & 12 & 1.75 (1.41 to 2.16$)$ & 83.5 & $<0.01$ \\
\hline Female & 9 & 0.97 (0.96 to 0.98$)$ & 71.3 & $<0.01$ & 10 & $1.46(1.29$ to 1.66$)$ & 34.2 & 0.13 \\
\hline
\end{tabular}

*Number of data points.

$\dagger 4 / 14$ estimates included are from models with multiple adjustments rather than standard adjustments of age, sex, and body size. †From Cochran's Q statistic.

$\S$ Total numbers differ for sex stratified meta-analyses for following reasons: per unit grip strength estimates include three studies of men only, two of women only, and two that had combined both sexes and did not have sex specific estimates also available (unstratified summary hazard ratio for comparison with sex stratified estimates 0.97 (0.96 to 0.98), $n=19, I^{2}=86.6 \%$, P $<0.01$ ); grip strength quarter comparison estimates include four studies of men only and two of women only (unstratified summary hazard ratio for comparison $1.61(1.43$ to 1.81$), n=22, I^{2}=73.9 \%, P<0.01$ ).

Grip strength and mortality

A total of 23 sets of results from tests of the association between grip strength and mortality were available, and these were all from unique studies with the exception of one study (the Honolulu Heart Program). Different authors used this one study to contribute two sets of results, but as one author provided effect estimates for the per unit change in grip strength and the other provided results of comparisons between quarters, ${ }^{2533}$ we could include both in meta-analyses without the same study population being included more than once in the same meta-analysis.

Meta-analysis of the association between a unit change in grip strength and mortality was based on
13 studies, one of which contributed two data points as men and women had been analysed separately (fig 3). ${ }^{30}$ Two other studies were not included: one because it had used the sum of grip strength in both hands, ${ }^{21}$ when all other studies had used the maximum measure achieved in one hand or an average per hand, and the other because grip strength had been measured in $\mathrm{N} / \mathrm{m}^{2}$ rather than $\mathrm{kg}{ }^{26}$ (We instead included these two studies in the meta-analyses of comparisons of quarters described below.)

Most of the 13 studies (with a total of 44636 participants) included in this first meta-analysis found that higher grip strength was associated with lower subsequent mortality; the overall summary hazard ratio of

Table 2 |Summary of results from studies of grip strength not included in meta-analyses

\begin{tabular}{|c|c|c|c|c|}
\hline Study name and reference $/ \mathrm{s}^{*}$ & $\begin{array}{l}\text { Total No (No of } \\
\text { deaths) }\end{array}$ & $\begin{array}{l}\text { Category comparison/value of } \\
\text { unit change }\end{array}$ & Effect estimate $(95 \% \mathrm{Cl})$ & Adjustments \\
\hline $\begin{array}{l}\text { Prospective Japanese study, Fujita } \\
\text { et al } 1995^{15}\end{array}$ & $\begin{array}{l}\text { Men } 2068(113) \text {; } \\
\text { women: } 1988 \\
(42)\end{array}$ & $\begin{array}{l}\text { Low } v \text { high performance (as judged } \\
\text { against a standard) }\end{array}$ & $\begin{array}{l}\text { Relative risk: men } 1.92 \text { (1.16 to } \\
\text { 3.16); women } 0.84 \text { (0.38 to } 1.86)\end{array}$ & Age \\
\hline $\begin{array}{l}\text { EVERGREEN project, Laukkanen et } \\
\text { al } 1995^{20}\end{array}$ & $463(74)$ & Below $v$ above mean & Odds ratio 1.86 (1.13 to 3.07 ) & Age, sex \\
\hline $\begin{array}{l}\text { Edinburgh Longitudinal Study of } \\
\text { Ageing, Milne and Maule } 1984^{22}\end{array}$ & $483(135)$ & NA & $\begin{array}{l}\text { No effect estimates presented- } \\
\text { mean baseline grip strength lower } \\
\text { in people who died during follow- } \\
\text { up than in those who survived }\end{array}$ & NA \\
\hline $\begin{array}{l}\text { Precipitating Events Project, } \\
\text { Rothman et al } 2008^{28}\end{array}$ & $754(283)$ & $\begin{array}{l}\text { Weak (that is, lower than sex and } \\
\text { body mass index specific } \\
\text { threshold) } v \text { not weak }\end{array}$ & Hazard ratio: 1.8 (1.3 to 2.5 ) & $\begin{array}{l}\text { Age, sex, race, } \\
\text { education, chronic } \\
\text { conditions }\end{array}$ \\
\hline
\end{tabular}


Table $3 \mid$ Results from stratified meta-analyses of age, sex, and body size adjusted hazard ratios of associations of walking speed and chair rise time with all cause mortality: lowest versus highest quarter comparison

\begin{tabular}{|c|c|c|c|c|c|c|c|c|}
\hline \multirow[b]{2}{*}{ Stratification } & \multicolumn{4}{|c|}{ Walking speed } & \multicolumn{4}{|c|}{ Chair rise time } \\
\hline & No* & $\begin{array}{l}\text { Summary hazard ratio } \\
(95 \% \mathrm{Cl})\end{array}$ & $12(\%)$ & $\mathrm{P}$ value $†$ & $\mathrm{No}^{\star}$ & $\begin{array}{l}\text { Summary hazard } \\
\text { ratio }(95 \% \mathrm{Cl})\end{array}$ & I2 (\%) & $\mathrm{P}$ value $\uparrow$ \\
\hline None & 5 & 2.87 (2.22 to 3.72$)$ & 25.2 & 0.25 & 5 & $1.96(1.56$ to 2.46$)$ & 81.9 & $<0.01$ \\
\hline \multicolumn{9}{|c|}{$\begin{array}{l}\text { Mean age at baseline } \\
\text { (years): }\end{array}$} \\
\hline$\leq 60$ & 0 & - & - & - & 0 & - & & \\
\hline $61-70$ & 1 & $6.25(2.79$ to 14.02$)$ & - & - & 0 & - & 81.9 & $<0.01$ \\
\hline$>70$ & 4 & 2.68 (2.14 to 3.35$)$ & 0 & 0.71 & 5 & 1.96 (1.56 to 2.46$)$ & & \\
\hline \multicolumn{9}{|c|}{ Length of follow-up (years): } \\
\hline$\leq 5$ & 4 & 3.11 (2.37 to 4.09$)$ & 13.3 & 0.33 & 1 & 1.90 (1.26 to 2.87$)$ & - & - \\
\hline $6-10$ & 1 & 2.16 (1.38 to 3.38$)$ & - & - & 3 & 2.14 (1.86 to 2.48$)$ & 8.7 & 0.34 \\
\hline $11-20$ & 0 & - & - & - & 1 & $1.50(1.38$ to 1.63$)$ & - & - \\
\hline$>20$ & 0 & - & - & - & 0 & - & - & - \\
\hline \multicolumn{9}{|l|}{ Region of study: } \\
\hline North America & 2 & 3.95 (1.89 to 8.28$)$ & 61.9 & 0.11 & 3 & $1.85(1.42$ to 2.41$)$ & 88.0 & $<0.01$ \\
\hline Japan & 0 & - & - & - & 0 & - & - & - \\
\hline Other & 3 & 2.61 (2.02 to 3.37$)$ & 0 & 0.54 & 2 & 2.26 (1.58 to 3.23$)$ & 27.7 & 0.24 \\
\hline \multicolumn{9}{|l|}{ Sexł: } \\
\hline Male & 4 & 2.65 (2.01 to 3.48$)$ & 0 & 0.58 & 3 & 2.17 (1.82 to 2.58$)$ & 17.3 & 0.30 \\
\hline Female & 4 & 3.19 (2.20 to 4.63$)$ & 6.7 & 0.36 & 3 & 1.77 (1.36 to 2.30$)$ & 67.0 & 0.05 \\
\hline
\end{tabular}

*Number of data points.

†From Cochran's Q statistic.

$\ddagger$ Total numbers differ for sex stratified meta-analyses for following reasons: walking speed quarter comparison estimates include one study of men only and one study of women only (unstratified summary hazard ratio for comparison 2.83 ( 2.28 to 3.51 ), $n=8, I^{2}=0 \%, P=0.56$ ); chair rise time quarter comparison estimates include two studies of men only and two studies of women only (unstratified summary hazard ratio for comparison 2.00 (1.62 to 2.46 ), $\left.n=6, I^{2}=78.1 \%, P<0.01\right)$.

\section{Study author/s (sex) (total No; No of deaths)}

\author{
Al Snih (B) (2488; 507) \\ Cawthon and Ensrud (MrOS) (M) $(5631 ; 1070)$ \\ Cawthon and Ensrud (SOF) (F) (9700; 5536) \\ Cesari 2008* (B) $(335 ; 71)$ \\ Gale (B) $(800 ; 756)$ \\ Katzmarzyk (B) $(8148 ; 269)$ \\ Klein (B) $(2612 ; 194)$ \\ Newman* (B) $(2292 ; 286)$ \\ Rantanen (M) (6040; 2900) \\ Sasaki (B) $(4821 ; 2407)$ \\ Shibata* (M) (192; 59) \\ Shibata* (F) $(221 ; 43)$ \\ Syddall (B) $(714 ; 52)$ \\ Takata* (B) $(642 ; 94)$ \\ Overall: $\left.\right|^{2}=89.5 \%, 95 \% \mathrm{Cl} 84 \%$ to $93 \%, \mathrm{P}<0.001$
}

Between study variance $=0.0002$

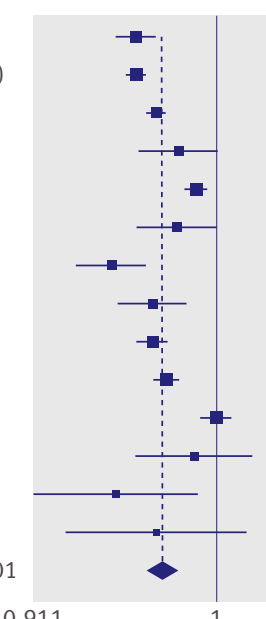

0.911

\section{Hazard ratio}

(95\% Cl)

Hazard ratio per 1 kg increase in grip strength

Fig $3 \mid$ Hazard ratios of mortality per $1 \mathrm{~kg}$ increase in grip strength with adjustment for age, sex (where appropriate), and body size. $\mathrm{B}=$ both sexes; $\mathrm{F}=$ women only; $\mathrm{M}=$ =men only; MrOS=0steoporotic Fractures in Men Study; SOF=Study of Osteoporotic Fractures. *Estimates adjusted for multiple factors as results from models adjusted for age, sex, and body size were not available. Adjustments were as follows: Cesari (2008)—age, sex, body mass index (BMI), cognitive performance, number of clinical conditions, albumin, total cholesterol; Newmanage, sex, race, height, smoking, physical activity, number of chronic conditions, education, interleukin-6, Center for Epidemiologic Studies Depression scale (CES-D), DXA body composition; Shibata—blood pressure, cholesterol, albumin, visual retention, education, BMI, history of chronic diseases, alcohol, smoking, activities of daily living, electrocardiographic changes; Takata-sex, smoking, BMI, systolic blood pressure, marital status, total cholesterol, glucose, complications from prevalent disease

mortality associated with a $1 \mathrm{~kg}$ increase in grip strength estimated from a random effects model was 0.97 (95\% confidence interval 0.96 to 0.98$)$ with adjustment for age, sex (where appropriate), and body size or with multiple adjustments for four studies (see footnote to fig 3). Although all effect estimates were in the same direction, we found evidence of heterogeneity between studies $\left(\mathrm{I}^{2}=89.5 \%, 95 \%\right.$ confidence interval $84 \%$ to 93\%; P from Q statistic<0.001). However, when we stratified the meta-analyses by the pre-specified characteristics and did meta-regression analyses we found no clear evidence that any of these factors explained the heterogeneity (table 1). Removal of each study from the meta-analyses did not greatly affect estimates of the level of heterogeneity (results not shown). Findings were similar when we analysed results from models adjusted for age and sex only.

Effect estimates from 14 studies (53 476 participants) that had compared quarters of grip strength were available for inclusion in meta-analyses (fig 4). Most of these studies found that people in the weakest sex specific quarter of grip strength had significantly higher rates of mortality than did those in the strongest quarter; the overall summary hazard ratio of mortality comparing the lowest with the highest quarter was 1.67 (1.45 to 1.93) with adjustment for age, sex, and body size. Summary hazard ratios from the meta-analyses of effect estimates comparing the second weakest and second strongest quarter with the strongest quarter showed a graded effect (fig 5). 
Hazard ratio (95\% Cl)

Ahmad and Bath (B) $(927 ; 812)$

Al Snih (B) (2488; 507)

Anstey (B) (1120; 463)

Cawthon and Ensrud (MrOS) (M) (5631; 1070)

Cawthon and Ensrud (SOF) (F) $(9700 ; 5536)$

Gale (B) $(800 ; 756)$

Katzmarzyk (B) $(8148 ; 269)$

Klein (B) $(2612 ; 194)$

Metter (M) (1071; 533)

Rolland (F) (7050; 722)

Sasaki (B) $(4821 ; 2407)$

Syddall (B) $(714 ; 52)$

Van den Beld (M) $(402 ; 179)$

Willcox (M) (7992; 6963)

Overall: $I^{2}=84.0 \%, 95 \% \mathrm{Cl} 74 \%$ to $90 \%, \mathrm{P}<0.001$

Between study variance $=0.05$

$$
0.19
$$

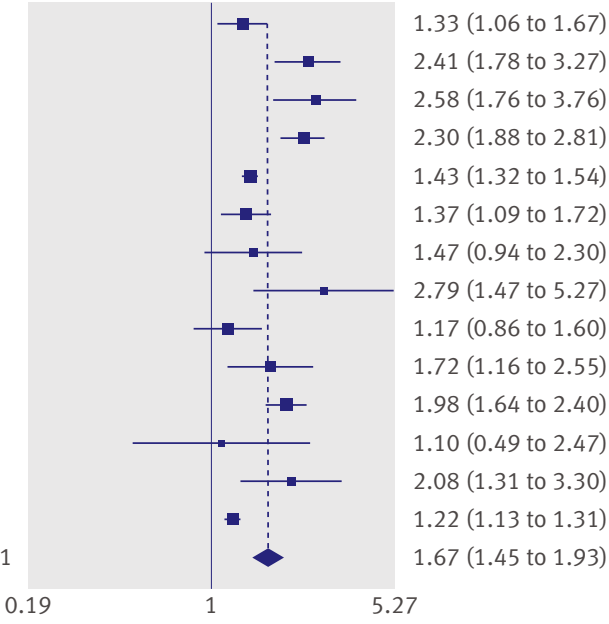

Hazard ratio lowest $\boldsymbol{v}$ highest quarter of grip strength

Fig 4 | Hazard ratios of mortality comparing weakest with strongest quarter of grip strength with adjustment for age, sex (where appropriate), and body size. B=both sexes; $F=$ women only; M=men only; MrOS=Osteoporotic Fractures in Men Study; SOF=Study of Osteoporotic Fractures

Although most of the estimates from comparisons of quarters were in the same direction, we found evidence of heterogeneity between studies $\left(\mathrm{I}^{2}=84.0 \%, 74 \%\right.$ to $90 \%$; P from Q statistic $<0.001)$. When we stratified meta-analyses (table 1), the association between grip strength and mortality seemed to be weaker in studies with an average age at baseline under 60 years compared with studies with an older average age at baseline and also in studies with follow-up of more than 20 years compared with studies with shorter follow-up. We found further evidence of a weaker association between grip strength and mortality in studies with longer follow-up in meta-regression analyses comparing the weakest and strongest quarters of grip strength $(\mathrm{P}=0.054$ from permutation test controlling for multiple testing). The inclusion of follow-up time reduced the estimate of between study variance from 0.06 to 0.02 , and the variation in effect size by follow-up time was independent of age $(\mathrm{P}=0.065$ for length of followup from permutation test). We found no evidence from meta-regression analyses in support of differences in summary estimates between categories of the other pre-specified characteristics, and the removal of each study from meta-analyses did not greatly affect estimates of the level of heterogeneity.

Of the four studies of grip strength that could not be included in at least one of the meta-analyses, most results were consistent with the findings from metaanalyses (table 2). ${ }^{15202228}$ The one exception was among women in the study by Fujita et al. ${ }^{15}$

\section{Walking speed and mortality}

A total of 16 sets of results from analyses of the association between walking speed or time and mortality were available; analyses were done in 11 different study populations. The Hispanic Established Population for the Epidemiological Study of the Elderly (H-

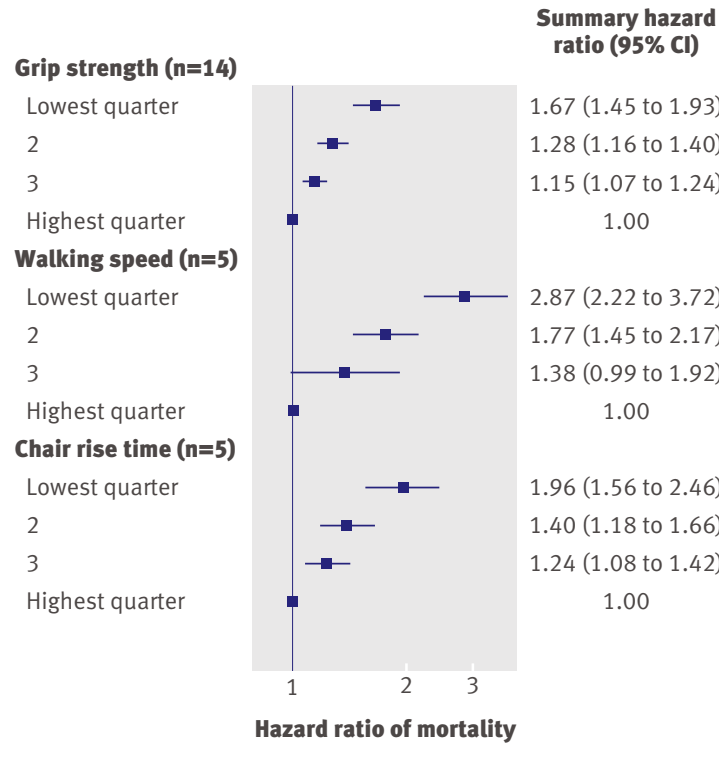

Fig 5 | Summary hazard ratios of mortality from meta-analyses comparing each quarter of grip strength, walking speed, and chair rise time with highest quarter, including results adjusted for age, sex (where appropriate), and body size ( $n=$ number of data points included in meta-analysis)

EPESE) ${ }^{103536}$ and another unnamed US study ${ }^{171824}$ had both been used three times, and the Health, Aging and Body Composition (ABC) study had been used twice, ${ }^{1214}$, at different follow-up times (web table A).

We had seven sets of results in the form of comparisons of quarters, but three were based on the same study population (H-EPESE) and we included only one set of these (those with the requested standard adjustments $\left.{ }^{10}\right)$ in the main meta-analysis. These five studies (14692 participants) all found that people in the slowest quarter of walking speed had significantly higher mortality rates than did those in the fastest quarter (fig 6); the overall summary hazard ratio of mortality comparing the slowest with the fastest quarter was 2.87 (2.22 to 3.72) with adjustment for age, sex, and body size. Heterogeneity was moderate $\left(\mathrm{I}^{2}=25.2 \%\right.$, $0 \%$ to $70 \%$; P from Q statistic $=0.25$ ), and the studies varied little in the pre-specified characteristics that could have explained this (table 3). Summary hazard ratios from the meta-analyses of effect estimates comparing the second slowest and second fastest quarters with the fastest quarter were also consistent and showed a graded effect (fig 5). Findings were similar when we re-ran meta-analyses including estimates from the other analyses of H-EPESE in place of those included in the main meta-analysis; the overall summary hazard ratios of mortality comparing the slowest with the fastest quarter estimated from random effects models were 2.99 (2.24 to 4.00 ) and 2.58 (1.83 to 3.64) when we included results from analyses by Markides et $\mathrm{al}^{35}$ and Ostir et $\mathrm{al}^{36}$ in place of those provided by $\mathrm{Al}$ Snih et al. ${ }^{10}$

The six studies not included in meta-analyses presented findings consistent with those from the 
Table 4 |Summary of results from studies of walking speed and chair rises not included in meta-analyses

\begin{tabular}{|c|c|c|c|c|}
\hline Study name and reference/s* & $\begin{array}{l}\text { Total No (No } \\
\text { of deaths) }\end{array}$ & $\begin{array}{l}\text { Category comparison/ } \\
\text { value of unit change }\end{array}$ & $\begin{array}{l}\text { Effect estimate } \\
(95 \% \mathrm{Cl})\end{array}$ & Adjustments \\
\hline \multicolumn{5}{|l|}{ Walking speed } \\
\hline $\begin{array}{l}\text { Health ABC study, Cesari et al } 2005^{12} \text { and } \\
2009^{14}\end{array}$ & $\begin{array}{l}1016 \\
(163) \dagger ; \\
3024(653) \ddagger\end{array}$ & $\begin{array}{l}\text { Speed }<1.00 \mathrm{~m} / \mathrm{s} v \geq 1.00 \\
\mathrm{~m} / \mathrm{s}\end{array}$ & $\begin{array}{l}\text { Relative risk } 1.64 \\
\text { (1.14 to } 2.37) \dagger ; 1.49 \\
(1.23 \text { to } 1.80) \ddagger\end{array}$ & $\begin{array}{l}\text { Age, sex, race, study site, smoking, BMI, } \\
\text { MMSE score, physical activity, } \\
\text { comorbidities (and also alcohol } \\
\text { consumption and education for } 6.9 \text { year } \\
\text { follow-up) }\end{array}$ \\
\hline ilSIRENTE, Cesari et al $2008^{13}$ & $335(71)$ & Per 1 SD increase & $\begin{array}{l}\text { Hazard ratio } 0.73 \\
(0.54 \text { to } 0.99)\end{array}$ & $\begin{array}{l}\text { Age, sex, BMI, cognitive performance, } \\
\text { No of clinical conditions, albumin, total } \\
\text { cholesterol }\end{array}$ \\
\hline $\begin{array}{l}\text { Unnamed US study, Hardy et al } 2007^{17} \text { and } \\
2008^{18} \text {; Perera et al } 2005^{24}\end{array}$ & $439(88)$ & Per $0.1 \mathrm{~m} / \mathrm{s}$ increase & $\begin{array}{l}\text { Hazard ratio } 0.87 \\
(0.78 \text { to } 0.98) \S\end{array}$ & $\begin{array}{l}\text { Age, sex, hospital admission, No of } \\
\text { comorbidities, activities of daily living }\end{array}$ \\
\hline EVERGREEN project, Laukkanen et al $1995^{20}$ & $466(74)$ & $\begin{array}{l}\text { Below } v \text { above mean } \\
\text { speed }\end{array}$ & $\begin{array}{l}\text { Hazard ratio } 1.98 \\
(1.18 \text { to } 3.34)\end{array}$ & Age, sex \\
\hline $\begin{array}{l}\text { Cardiovascular Health Study, Rosano et al } \\
2008^{27}\end{array}$ & $3156(704)$ & Per $1 \mathrm{~m} / \mathrm{s}$ increase & $\begin{array}{l}\text { Hazard ratio } 0.87 \\
\text { (0.78 to } 0.98)\end{array}$ & $\begin{array}{l}\text { Age, sex, race, education, digit symbol } \\
\text { substitution test score }\end{array}$ \\
\hline $\begin{array}{l}\text { Precipitating Events Project, Rothman et al } \\
2008^{28}\end{array}$ & $754(283)$ & Slow $v$ not slow & $\begin{array}{l}\text { Hazard ratio } 2.7(2.0 \\
\text { to } 3.7)\end{array}$ & $\begin{array}{l}\text { Age, sex, race, education, chronic } \\
\text { conditions }\end{array}$ \\
\hline \multicolumn{5}{|l|}{ Chair rises } \\
\hline Health ABC study, Cesari et al $2009^{14}$ & $3024(653)$ & $\begin{array}{l}\text { Time for } 5 \text { rises } \geq \\
17 \text { seconds } v< \\
17 \text { seconds }\end{array}$ & $\begin{array}{l}\text { Hazard ratio } 1.40 \\
(1.17 \text { to } 1.68)\end{array}$ & $\begin{array}{l}\text { Age, sex, race, study site, smoking, BMI, } \\
\text { MMSE score, physical activity, } \\
\text { comorbidities, alcohol consumption, } \\
\text { education }\end{array}$ \\
\hline ilSIRENTE, Cesari et al $2008^{13}$ & $335(71)$ & $\begin{array}{l}\text { Per } 1 \text { SD increase in chair } \\
\text { rise score-from } 0 \\
\text { (unable) to } 4 \text { ( } \leq \\
11 \text { seconds) }\end{array}$ & $\begin{array}{l}\text { Hazard ratio } 0.51 \\
(0.36 \text { to } 0.72)\end{array}$ & $\begin{array}{l}\text { Age, sex, BMI, cognitive performance, } \\
\text { No of clinical conditions, albumin, total } \\
\text { cholesterol }\end{array}$ \\
\hline
\end{tabular}

BMI=body mass index; MMSE=mini-mental state examination.

*See web table A for further details of studies.

†4.9 year follow-up (on restricted sample).

$\ddagger 6.9$ year follow-up (on full sample).

§Results taken from Perera et al $2005,{ }^{24}$ but results from two other papers on this study are consistent. ${ }^{17,18}$

meta-analyses (table 4). All evidence supported an association between slower walking speed and higher mortality.

\section{Chair rise time and mortality}

All seven sets of results from analyses of the association between chair rise time and mortality were from unique studies. Five were in the form of comparisons of quarters and so could be included in meta-analyses. These five studies (28036 participants) all found that people in the slowest quarter of chair rise time had significantly higher mortality rates than did those in the fastest quarter (fig 7); the overall summary hazard ratio of mortality comparing the slowest with the fastest quarter was 1.96 (1.56 to 2.45) with adjustment for

\section{Study author/s (sex) (total No; No of deaths)}

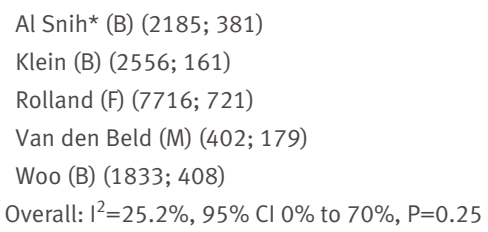

Between study variance $=0.02$

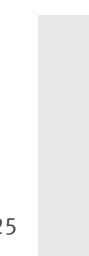

\section{Hazard ratio \\ (95\% Cl)}

$2.90(1.83$ to 4.60$)$

6.25 (2.79 to 14.02$)$

2.52 (1.37 to 4.63 )

2.16 (1.38 to 3.38$)$

3.00 (2.08 to 4.33$)$

2.87 (2.22 to 3.72$)$

14
Hazard ratio slowest $\boldsymbol{v}$ fastest quarter of walking speed

Fig 6| Hazard ratios of mortality comparing slowest with fastest quarter of walking speed with adjustment for age, sex (where appropriate), and body size. B=both sexes; F=women only; $\mathrm{M}=$ men only. *When results from analyses of $\mathrm{H}$-EPESE by Markides et al and Ostir et al were included in this meta-analysis in place of Al Snih's results, the findings were unchanged age, sex, and body size. Although all effect estimates were in the same direction, we found evidence of a high degree of heterogeneity between studies $\left(\mathrm{I}^{2}=81.9 \%, 58 \%\right.$ to $92 \%$; P from $\mathrm{Q}$ statistic $\left.<0.001\right)$. When we stratified the meta-analyses by the pre-specified characteristics (table 3), the effect seemed to be stronger in men than in women, but we had too few data points to investigate this further. The variation in the other characteristics was also insufficient to explain the heterogeneity, and the removal of each study from meta-analyses did not affect estimates of the level of heterogeneity (results not shown). Summary hazard ratios from the meta-analyses of effect estimates comparing the second slowest and second fastest quarters with the fastest quarter were also consistent and showed a graded effect (fig 5). Three of the studies also reported effect estimates from comparisons of people unable to do chair rises with those in the fastest quarter; the summary hazard ratio for mortality from a meta-analysis of these three results suggested that those unable to do chair rises had the highest rates of mortality $(4.09,2.24$ to 4.42$)$.

The findings from the two studies not included in the meta-analysis (table 4) were consistent with those from the meta-analysis and also reported that slower chair rise time was associated with higher mortality.

\section{Standing balance and mortality}

All five sets of results from analyses testing the association between standing balance and mortality were 


\begin{tabular}{|c|c|c|c|c|}
\hline $\begin{array}{l}\text { Study name and reference/ } \\
\mathrm{s}^{\star}\end{array}$ & $\begin{array}{l}\text { Total No (No } \\
\text { of deaths) }\end{array}$ & $\begin{array}{l}\text { Category comparison/value of unit } \\
\text { change }\end{array}$ & $\begin{array}{l}\text { Effect estimate } \\
(95 \% \mathrm{Cl})\end{array}$ & Adjustments \\
\hline $\begin{array}{l}\text { Health ABC study, Cesari et al } \\
2009^{14}\end{array}$ & 3024 (653) & $\begin{array}{l}\text { Balance }<53 \text { seconds } v \geq 53 \text { seconds (note: } \\
\text { max score } 90 \text { seconds) }\end{array}$ & $\begin{array}{l}\text { Hazard ratio } 1.35 \\
(1.12 \text { to } 1.62)\end{array}$ & $\begin{array}{l}\text { Age, sex, race, study site, smoking, } \\
\text { BMI, MMSE score, physical activity, } \\
\text { comorbidities, alcohol } \\
\text { consumption, education }\end{array}$ \\
\hline ilSIRENTE, Cesari et al $2008^{13}$ & $335(71)$ & $\begin{array}{l}\text { Per } 1 \text { SD increase in standing balance score } \\
\text {-from } 0 \text { (unable) to } 4 \text { (hold tandem stand } \\
\text { for } 10 \text { seconds) }\end{array}$ & $\begin{array}{l}\text { Hazard ratio } 0.77 \\
(0.60 \text { to } 1.00)\end{array}$ & $\begin{array}{l}\text { Age, sex, BMI, cognitive } \\
\text { performance, No of clinical } \\
\text { conditions, albumin, total } \\
\text { cholesterol }\end{array}$ \\
\hline EPESE, Guralnik et al $1994^{43}$ & $5264(1741)$ & $\begin{array}{l}\text { 1) Unable to hold side by side stand } v \text { able } \\
\text { to hold tandem stand for } 10 \text { seconds; } 2 \text { ) } \\
\text { Able to hold side by side stand for } \\
10 \text { seconds but unable to hold semi- } \\
\text { tandem stand for } 10 \text { seconds } v \text { able to hold } \\
\text { tandem stand for } 10 \text { seconds }\end{array}$ & $\begin{array}{l}\text { 1) Hazard ratio } 3.54 \\
(3.04 \text { to } 4.13) ; 2) \\
1.78(1.51 \text { to } 2.09)\end{array}$ & Age, sex, height, weight \\
\hline $\begin{array}{l}\text { EPIDOS study, Rolland et al } \\
2006^{26}\end{array}$ & $7092(722)$ & $\begin{array}{l}\text { Lowest ( } 0-20 \text { seconds) } v \text { highest third ( } \\
27-30 \text { seconds) }\end{array}$ & $\begin{array}{l}\text { Hazard ratio } 1.57 \\
(1.32 \text { to } 1.87)\end{array}$ & Age, sex, body mass index \\
\hline $\begin{array}{l}\text { Study of Fukuoka Prefecture } \\
\text { residents, Takata et al } \\
2007^{32}\end{array}$ & $551(72)$ & Per 1 unit change in balance time & $\begin{array}{l}\text { Hazard ratio } 0.99 \\
(0.97 \text { to } 1.01)\end{array}$ & $\begin{array}{l}\text { Sex, smoking, BMI, systolic blood } \\
\text { pressure, marital status, total } \\
\text { cholesterol, glucose, complications } \\
\text { from prevalent disease }\end{array}$ \\
\hline
\end{tabular}

$\mathrm{BMI}=$ body mass index; $\mathrm{MMSE}=$ mini-mental state examination.

* See web table A for further details of studies.

from unique studies. However, as standing balance had not been measured and categorised in comparable ways across studies, we could not do meta-analyses of these results. Although all five studies found some evidence that poorer performance in standing balance tests was associated with higher mortality rates, these associations were not all statistically significant at conventional levels (table 5).

\section{DISCUSSION}

We have found evidence of associations between all four measures of physical capability investigated (grip strength, walking speed, chair rises, and standing balance) and all cause mortality. People in community dwelling populations who perform less well in these tests were consistently found to be at higher risk of death. The estimates from meta-analyses for grip strength, walking speed, and chair rises show a doseresponse relation. With the exception of grip strength, studies have been done exclusively in older populations, and most have relatively short follow-up, so whether similar associations would be found at younger ages or after participants have been

\section{Study author/s (sex) (total No; No of deaths)}

Cawthon and Ensrud (MrOS) (M) (5712; 1091) Cawthon and Ensrud (SOF) (F) (9688; 5509) Guralnik (B) $(5231 ; 1423)$

Rolland (F) (7012; 721)

Van den Beld (M) $(393 ; 176)$

Overall: $I^{2}=81.9 \%, 95 \% \mathrm{Cl} 58 \%$ to $92 \%$, P $<0.001$

Between study variance $=0.05$

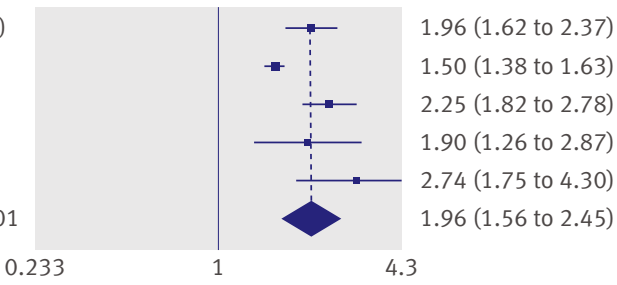

0.233

\section{Hazard ratio} (95\% CI)

Hazard ratio slowest $v$ fastest quarter of chair rise time

Fig $7 \mid$ Hazard ratios of mortality comparing slowest with fastest quarter of chair rise time with adjustment for age, sex (where appropriate), and body size. $B=$ both sexes; $F=$ women only; $\mathrm{M}=$ men only; MrOS=Osteoporotic Fractures in Men Study; SOF=Study of Osteoporotic Fractures followed-up for longer than 10 years is unclear. For grip strength, we found evidence of an association even in populations with an average age at baseline of less than 60 years, although the association weakened with increasing length of follow-up.

\section{Explanation of findings}

Several possible explanations exist, which are not necessarily exclusive, for finding associations between objective measures of physical capability and mortality in community dwelling populations. Firstly, these findings could be explained by confounding (for example, by socioeconomic position or levels of physical activity), as effect estimates have only been adjusted for age, sex, and body size. These factors were considered to be the most likely confounders yet did not explain the associations of the physical capability measures with mortality. Apart from these, no standard set of multiple adjustments across papers existed and we thought that requesting further adjustments would have affected the response from study authors and led to inconsistencies in adjustments across studies.

Secondly, these measures of physical capability could be markers of disease and general health status. Some of the community dwelling populations included in this review consisted of people with diseases or comorbidities that were not considered severe enough to warrant exclusion from the study but that may have affected both their physical performance and mortality risk. This could definitely apply to walking speed, chair rises, and standing balance, for which studies have been done only in older populations with shorter follow-up. However, this seems less likely to fully explain associations between grip strength and mortality, as these were also found in studies with follow-up over 20 years, in younger populations in which the prevalence of sub-clinical disease and existing comorbidities would be lower, and in studies that by 
the nature of their design (for example, recruitment of men from the active workforce) excluded people with health problems. ${ }^{25}$

A related possibility is that underlying ageing processes led to poorer performance and a higher probability of chronic disease and death. Walking speed, chair rising, and standing balance require strength, balance, and motor control; walking speed and chair rising also require muscle power and speed and adequate cardiorespiratory function; standing balance requires mental concentration. These functions decline with age, may co-vary, and contribute to the risk of frailty. The progressive dysregulation of homoeostatic equilibrium across multiple systems may be the biological basis of frailty; common pathways proposed include endocrine dysfunction, inflammation, oxidative stress, and disequilibrium between the sympathetic and parasympathetic systems. ${ }^{55}$

Functional status in later life reflects the peak achieved during growth and development, as well as the rate of decline. Thus, the relation between these measures of physical capability, even when measured at younger ages, and mortality could also reflect initial differences in development that affect both. Evidence that early growth, cognitive and motor development, and childhood social environment are associated with adult physical capability, chronic disease, and mortality support this possibility. ${ }^{56-62}$

\section{Heterogeneity}

Many of the estimates of $\mathrm{I}^{2}$ calculated in these metaanalyses would be judged to be high. ${ }^{49}$ We have presented summary, overall estimates from meta-analyses despite this, as most effect estimates from individual studies were in the same direction and doing meta-analyses has been argued to still be appropriate. ${ }^{6364}$ Furthermore, the value of $\mathrm{I}^{2}$ depends on both the within study and the between study variance, ${ }^{4865}$ and as many of the studies included in this review have precise estimates (figs 3 and 4), either because the study population was large or a high proportion of participants died, the values of $\mathrm{I}^{2}$ will have been affected by this. However, these summary estimates, which are an average of estimates across populations with different characteristics, should be cited with caution, and the reasons for finding these levels of heterogeneity should be explored.

Insufficient variation often existed in the characteristics we proposed a priori as possible sources of heterogeneity to allow us to examine their role in explaining heterogeneity fully-for example, four of the five studies of walking speed and all five studies of chair rise time included in meta-analyses were in populations aged over 70. However, meta-regression analyses of comparisons of quarters of grip strength suggested that associations with mortality were weaker in those studies with longer follow-up, even after adjustment for age. Comorbidities at the time of assessment of capability, which would increase short term mortality, may be more likely to explain the association between grip strength and mortality in studies with shorter follow-up. With increasing length of follow-up, the proportional hazards assumption within a study may be violated.

In addition to the characteristics investigated, many others vary between studies and could result in heterogeneity. These include differences in exclusion criteria, the instruments used, the main causes of death, levels of underlying comorbidity, and ethnic diversity.

\section{Implications}

This review has highlighted the paucity of studies that have measured physical capability in younger populations with subsequent follow-up for mortality. This situation is expected to change; these measures are being introduced in studies of younger populations as overall markers of functioning at the multi-system level, rather than as markers of severity and stage of specific chronic diseases. ${ }^{66}$ However, investigation of associations with mortality in studies with measurement of capability at younger ages will obviously need lengthy follow-up. Research is also needed to examine the associations between changes in capability with age and mortality, as a steep decline in physical capability may be a better predictor of mortality than is the absolute level at a single point in time. In addition, associations between these measures and cause specific mortality and other health outcomes may help to elucidate the pathways underlying the associations with all cause mortality, although few studies identified reported on these. Elucidating the underlying biological pathways that link poorer capability to mortality will inform the development of effective interventions.

We chose to examine the relation between each individual measure of physical capability, by using a standardised exposure measurement (comparisons of quarters), and mortality. The rationale behind this is that a variety of composite scores exist that are derived by using these measurements in combination, but whether results with such scores are driven by one measure or whether they each make a similar contribution is unclear. Although our findings suggest that all four measures of physical capability assessed are associated with all cause mortality, the relative paucity of data for walking speed, chair rises, and standing balance makes us cautious about drawing conclusions on their relative strengths. As these measures of physical capability are highly correlated with each other, more studies are needed that consider the value of each additional test once the findings for one test are known. ${ }^{14}$ For clinical practice, investigating whether a derived composite score representing overall lower or upper body function, such as the short physical performance battery score ${ }^{43}$ or one of the frailty indices, may be a stronger predictor of mortality than any of the individual measures are by themselves would be of interest.

The associations found between measures of physical capability and mortality seem to operate across the whole range of ability, with no apparent threshold effect. Therefore, if these measures were to be used as screening tools, clinicians and researchers would need to identify thresholds with caution and recognise that 
differences in the most appropriate place to set these may exist, depending on the characteristics of the population to be screened. Ultimately, randomised controlled trials will be needed to determine whether interventions aimed at improving physical capability are effective at improving capability and as a consequence are effective at reducing morbidity and mortality.

\section{Strengths and limitations}

The main strengths of this systematic review are its inclusion of several measures of physical capability and its inclusion of as many relevant studies as possible by making contact with study authors. By following a strict protocol, testing a priori hypotheses, and including unpublished results, we have minimised bias.

The study also has some limitations, although none of these affects our conclusions. Results from each study are based on the assumption of proportional hazards, which may not hold in all studies. The metaregression analyses were likely to be underpowered, as were the formal tests of publication bias, especially for walking speed and chair rises for which we had less than the recommended number of data points. That the funnel plots and formal statistical tests produced no clear evidence of publication bias should thus be interpreted with caution. However, our success in obtaining unpublished results should limit publication bias.

\section{Conclusions}

This review shows the value of objective measures of physical capability as predictors of subsequent mortality in older community dwelling populations. Grip strength measured at younger ages also predicted mortality, but whether walking speed, chair rise time, and standing balance performance are associated with mortality in younger populations remains to be seen.

We thank the following people who helped to provide data for this review: Kaarin Anstey (Ageing Research Unit and Centre for Mental Health Research, Australian National University, Canberra, Australia), Cora L Craig (Canadian Fitness Survey), Peter Katzmarzyk (Canadian Fitness Survey, Pennington Biomedical Research Center), Ronald Klein, Michael D Knutson, Kristine E Lee (Department of Ophthalmology and Visual Sciences, University of Wisconsin, Madison, WI, USA), Kevin Morgan (School of Sport, Exercise and Health Sciences, Loughborough University, UK), Michiko Yamada, and Shoichiro Fujita.

We also thank all other members of the FALCon study team (Eleni Bakra, Michaela Benzeval, Fiona Matthews, and Graciela Muniz Terrera) for thei helpful comments and Hugh McGuire (National Collaborating Centre for Women's and Children's Health), who provided advice on systematic reviews and performing literature searches.

The HALCyon study team also includes Yoav Ben-Shlomo, Cyrus Cooper, Leone Craig, Ian Day, Richard Martin, Kate Tilling, Tamuno Alfred, Mike Gardner, John Gallacher, Ian Deary, John Starr, Paul Shiels, Thomas von Zglinicki, Humphrey Southall, Paula Aucott, Jane Elliott, Andrew Steptoe, Chris Power, Geraldine McNeill, Alison Lennox, Marcus Richards, Gita Mishra, Zeinab Mulla, Emily Lemelin, and James Goodwin.

The following are members of the Mortality Review Group, all of whom contributed equally to this work: Rabiah Ahmad (Universiti Teknologi Malaysia), Avan Aihie Sayer (MRC Epidemiology Resource Centre, University of Southampton), Soham Al Snih (Sealy Center on Aging), Peter A Bath (University of Sheffield), Peggy M Cawthon (California Pacific Medical Center Research Institute), J David Curb (Kuakini Medica Center and University of Hawaii), Kristine E Ensrud (University of Minnesota), Luigi Ferrucci (National Institute on Aging), Catharine R Gale
(MRC Epidemiology Resource Centre, University of Southampton), Jack M Guralnik (National Institute on Aging), Suzanne Ho (Chinese University of Hong Kong), Fumiyoshi Kasagi (Radiation Effects Research Foundation, Japan), Barbara E K Klein (University of Wisconsin-Madison), Valerie Lauwers-Cances (Service d'Epidémiologie, CHU Toulouse), Debbie A Lawlor (MRC Centre for Causal Analyses in Translational Epidemiology, University of Bristol), E Jeffrey Metter (National Institute on Aging), Kushang V Patel (National Institute on Aging), Taina Rantanen (University of Jyväskylä), Yves Rolland (University of Toulouse III), Hideo Sasaki (Hiroshima University School of Medicine), Holly Syddall (MRC Epidemiology Resource Centre, University of Southampton), Annewieke van den Beld (Erasmus Medical Center), Bradley Willcox (Kuakini Health System), Andrew K Wills (MRC Unit for Lifelong Health and Ageing), and Jean Woo (Chinese University of Hong Kong).

Contributors: $\mathrm{RC}, \mathrm{RH}$, and DK were involved in developing the study concept and design. RC and $\mathrm{RH}$ did the literature review and data extraction. RC, RH, Rabiah Ahmad, Avan Aihie Sayer, Soham Al Snih, Pete A Bath, Peggy M Cawthon, J David Curb, Kristine E Ensrud, Luigi Ferrucci, Catharine R Gale, Jack M Guralnik, Suzanne Ho, Fumiyoshi Kasagi, Barbara E K Klein, Valerie Lauwers-Cances, E Jeffrey Metter, Kushang V Patel, Taina Rantanen, Yves Rolland, Hideo Sasaki, Holly Syddall, Annewieke van den Beld, Bradley Willcox, and Jean Woo were involved in acquisition of results. Rabiah Ahmad (Nottingham Longitudinal Study of Activity and Ageing), Avan Aihie Sayer (Hertfordshire Ageing Study), Soham Al Snih (H-EPESE), Peter A Bath (Nottingham Longitudinal Study of Activity and Ageing), Peggy M Cawthon (MrOS and SOF), Kristine E Ensrud (MrOS and SOF), Catharine R Gale (Department of Health and Social Security Survey follow-up), Jack M Guralnik (EPESE), Suzanne Ho (Hong Kong Old Old Study), Barbara E K Klein (Beaver Dam Eye Study Cohort), Valerie Lauwers-Cances (EPIDOS study), E Jeffrey Metter (BLSA), Kushang V Patel (EPESE), Taina Rantanen (Honolulu Heart Program), Yves Rolland (EPIDOS study), Hideo Sasaki (Adult Health Study Cohort), Holly Syddall (Hertfordshire Ageing Study), Annewieke van den Beld (Zoetermeer Study), Bradley Willcox (Honolulu Heart Program and Honolulu Asia Aging Study), and Jean Woo (Hong Kong Old Old Study) were involved in analysing data. RC did the meta-analysis of results. RC, $\mathrm{RH}$, and DK were involved in interpretation of results. RC drafted the manuscript. All authors critically revised and approved the manuscript. RC is the guarantor.

Funding: This project was funded by a grant from the UK Medical Research Council Population Health Sciences Research Network. RC originally received support from this grant but is now receiving support from the HALCyon programme funded by the New Dynamics of Ageing (RES-353-25-0001). DK, RH, and Andrew K Wills are supported by the UK Medical Research Council. Debbie A Lawlor also works in a centre that is supported by the UK Medical Research Council. Work was also supported in part by the Intramural Research Program, National Institute on Aging, $\mathrm{NIH}$. The Osteoporotic Fractures in Men (MrOS) Study is supported by National Institutes of Health funding. The following institutes provide support: the National Institute of Arthritis and Musculoskeletal and Skin Diseases (NIAMS), the National Institute on Aging (NIA), the National Center for Research Resources (NCRR), and NIH Roadmap for Medical Research under the following grant numbers: U01 AR45580, U01 AR45614, U01 AR45632, U01 AR45647, U01 AR45654, U01 AR45583, U01 AG18197, U01-AG027810, and UL1 RR024140. The Study of Osteoporotic Fractures (SOF) is supported by National Institutes of Health funding. The National Institute on Aging (NIA) provides support under the following grant numbers: AG05407, AR35582, AG05394 AR35584, AR35583, R01 AG005407, R01 AG027576-22, 2 R01 AG005394-22A1, and 2 R01 AG027574-22A1. This research is also supported in part by National Institutes of Health grants EY03083 and EY016379 (Barbara E K Klein) and by the Research to Prevent Blindness (B E K Klein, senior scientific investigator award), New York, NY. The study sponsors played no role in study design; the collection, analysis, and interpretation of data; the writing of the article; or the decision to submit it for publication. The researchers have independence from their funders. Competing interests: All authors have completed the Unified Competing Interest form at www.icmje.org/col_disclosure.pdf (available on reques from the corresponding author) and declare that (1) no author has received support for the submitted work from any source other than those listed under the heading funding above; (2) Peggy M Cawthon has had relationships with Merck and Amgen, and Yves Rolland has had relationships with Amgen, Pierre Fabre, Cheisy, Novartis, and Servier, al of whom might have an interest in the submitted work in the previous 3 years; (3) no author's spouses, partners, or children have financial relationships that may be relevant to the submitted work; (4) no authors 


\section{WHAT IS ALREADY KNOWN ON THIS TOPIC}

Growing evidence indicates that simple objective measures of physical capability may be useful markers of future as well as current health

Interest is increasing in these tests and their potential use as simple screening tools

\section{WHAT THIS STUDY ADDS}

Despite heterogeneity between studies, consistent evidence shows associations between grip strength, walking speed, chair rise, and standing balance performance and all cause mortality in older community dwelling populations

The inverse association between grip strength and all cause mortality was also seen in younger populations

These measures may provide useful tools for identifying older people at higher risk of death

have any non-financial interests that may be relevant to the submitted work.

Ethical approval: All included studies had received the relevant ethical approval. No additional approval was required for this review.

Data sharing: No additional data available.

1 Kuh D, New Dynamics of Ageing Preparatory Network. A life course approach to healthy aging, frailty, and capability. J Gerontol A Biol SCi Med Sci 2007;62:717-21.

2 Harwood RH, Conroy SP. Slow walking speed in elderly people. $B M$ 2009;339:b4236.

3 Bergman H, Ferrucci L, Guralnik J, Hogan DB, Hummel S, Karunananthan S, et al. Frailty: an emerging research and clinical paradigm-issues and controversies. J Gerontol A Biol Sci Med Sci 2007;62:731-7

4 Rantanen T. Muscle strength, disability and mortality. Scand J Med Sci Sports 2003;13:3-8.

5 Bohannon RW. Hand-grip dynamometry predicts future outcomes in aging adults. / Geriatr Phys Ther 2008;31:3-10.

6 Stroup DF, Berlin JA, Morton SC, Olkin I, Williamson GD, Rennie D, et al. Meta-analysis of observational studies in epidemiology-a proposal for reporting. JAMA 2000;283:2008-12.

7 Moher D, Liberati A, Tetzlaff J, Altman DG. Preferred reporting items for systematic reviews and meta-analyses: the PRISMA statement. Ann Intern Med 2009;151:W65-94.

8 Cooper R, Kuh D, Cooper C, Gale CR, Lawlor DA, Matthews F, et al Objective measures of physical capability and subsequent health: a systematic review. Age Ageing [forthcoming].

9 Ahmad R, Bath PA. Identification of risk factors for 15-year mortality among community-dwelling older people using Cox regression and genetic algorithm. J Gerontol A Biol Sci Med Sci 2005;60:1052-8.

10 Al Snih S, Markides KS, Ray L, Ostir GV, Goodwin JS. Handgrip strength and mortality in older Mexican Americans. J Am Geriatr Soc 2002;50:1250-6.

11 Anstey KJ, Luszcz MA, Giles LC, Andrews GR. Demographic, health, cognitive, and sensory variables as predictors of mortality in very old adults. Psychol Aging 2001;16:3-11.

12 Cesari M, Kritchevsky SB, Penninx BW, Nicklas BJ, Simonsick EM, Newman AB, et al. Prognostic value of usual gait speed in wellfunctioning older people-results from the Health, Aging and Body Composition Study. J Am Geriatr Soc 2005;53:1675-80.

13 Cesari M, Onder G, Zamboni V, Manini T, Shorr RI, Russo A, et al. Physical function and self-rated health status as predictors of mortality: results from longitudinal analysis in the ilSIRENTE study. BMC Geriatr 2008;8:34.

14 Cesari M, Kritchevsky SB, Newman AB, Simonsick EM, Harris TB, Penninx BW, et al. Added value of physical performance measures in predicting adverse health-related events: results from the Health, Aging and Body Composition Study. J Am Geriatr Soc 2009;57:251-9.

15 Fujita Y, Nakamura Y, Hiraoka J, Kobayashi K, Sakata K, Nagai M, et al. Physical-strength tests and mortality among visitors to healthpromotion centers in Japan. J Clin Epidemiol 1995;48:1349-59.

16 Gale CR, Martyn CN, Cooper C, Sayer AA. Grip strength, body composition, and mortality. Int J Epidemiol 2007;36:228-35.

17 Hardy SE, Perera S, Roumani YF, Chandler JM, Studenski SA. Improvement in usual gait speed predicts better survival in older adults. J Am Geriatr Soc 2007;55:1727-34.

18 Hardy SE, Studenski SA. Fatigue predicts mortality in older adults. $J$ Am Geriatr Soc 2008;56:1910-4.

19 Katzmarzyk PT, Craig CL. Musculoskeletal fitness and risk of mortality. Med Sci Sports Exerc 2002;34:740-4.
20 Laukkanen P, Heikkinen E, Kauppinen M. Muscle strength and mobility as predictors of survival in 75-84-year-old people. Age Ageing 1995;24:468-73.

21 Metter EJ, Talbot LA, Schrager M, Conwit R. Skeletal muscle strength as a predictor of all-cause mortality in healthy men. J Gerontol A Bio Sci Med Sci 2002;57:B359-65.

22 Milne JS, Maule MM. A longitudinal study of handgrip and dementia in older people. Age Ageing 1984;13:42-8.

23 Newman AB, Kupelian V, Visser M, Simonsick EM, Goodpaster BH, Kritchevsky SB, et al. Strength, but not muscle mass, is associated with mortality in the health, aging and body composition study cohort. J Gerontol A Biol Sci Med Sci 2006;61:72-7.

24 Perera S, Studenski S, Chandler JM, Guralnik JM. Magnitude and patterns of decline in health and function in 1 year affect subsequent 5-year survival. J Gerontol A Biol Sci Med Sci 2005;60:894-900.

25 Rantanen T, Harris T, Leveille SG, Visser M, Foley D, Masaki K, et al. Muscle strength and body mass index as long-term predictors of mortality in initially healthy men. / Gerontol A Biol Sci Med Sci 2000;55:M168-73.

26 Rolland Y, Lauwers-Cances V, Cesari M, Vellas B, Pahor M, Grandjean $\mathrm{H}$. Physical performance measures as predictors of mortality in a cohort of community-dwelling older French women. Eur J Epidemiol 2006;21:113-22.

27 Rosano C, Newman AB, Katz R, Hirsch CH, Kuller LH. Association between lower digit symbol substitution test score and slower gait and greater risk of mortality and of developing incident disability in well-functioning older adults. J Am Geriatr Soc 2008;56:1618-25.

28 Rothman MD, Leo-Summers L, Gill TM. Prognostic significance of potential frailty criteria. J Am Geriatr Soc 2008;56:2211-6.

29 Sasaki H, Kasagi F, Yamada M, Fujita S. Grip strength predicts causespecific mortality in middle-aged and elderly persons. Am J Med 2007;120:337-42.

30 Shibata H, Haga H, Nagai H, Suyama Y, Yasumura S, Koyano W, et al. Predictors of all-cause mortality between ages 70 and 80: the Koganei study. Arch Gerontol Geriatr 1992;14:283-97.

31 Syddall H, Cooper C, Martin F, Briggs R, Aihie-Sayer A. Is grip strength a useful single marker of frailty? Age Ageing 2003;32:650-6.

32 Takata Y, Ansai T, Akifusa S, Soh I, Yoshitake Y, Kimura Y, et al. Physical fitness and 4-year mortality in an 80-year-old population. Gerontol A Biol Sci Med Sci 2007;62:851-8.

33 Willcox BJ, He Q, Chen R, Yano K, Masaki KH, Grove JS, et al. Midlife risk factors and healthy survival in men. JAMA 2006;296:2343-50.

34 Ottawa Hospital Research Institute. The Newcastle-Ottawa quality assessment scale. 2009. www.ohri.ca/programs/ clinical epidemiology/nosgen.pdf.

35 Markides KS, Black SA, Ostir GV, Angel RJ, Guralnik JM, Lichtenstein M. Lower body function and mortality in Mexican American elderly people. J Gerontol A Biol Sci Med Sci 2001;56:M243-7.

36 Ostir GV, Kuo YF, Berges IM, Markides KS, Ottenbacher KJ. Measures of lower body function and risk of mortality over 7 years of follow-up. Am J Epidemiol 2007;166:599-605.

37 Woo J, Ho SC, Yu ALM. Walking speed and stride length predicts 36 months' dependency, mortality, and institutionalization in Chinese aged 70 and older. J Am Geriatr Soc 1999;47:1257-60.

38 Cawthon PM, Marshall LM, Michael Y, Dam T, Ensrud KE, Barrett-Connor $\mathrm{E}$, et al. Frailty in older men: prevalence, progression, and relationship with mortality. J Am Geriatr Soc 2007;55:1216-23.

39 Ensrud KE, Ewing SK, Taylor BC, Fink HA, Cawthon PM, Stone KL, et al. Comparison of 2 frailty indexes for prediction of falls, disability, fractures, and death in older women. Arch Intern Med 2008;168:382-9.

40 Ensrud KE, Ewing SK, Cawthon PM, Fink HA, Taylor BC, Cauley JA, et al. A comparison of frailty indexes for the prediction of falls, disability, fractures, and mortality in older men. J Am Geriatr Soc 2009;57:492-8.

41 Fried LP, Kronmal RA, Newman AB, Bild DE, Mittelmark MB, Polak JF, et al. Risk factors for 5-year mortality in older adults-the cardiovascular health study. JAMA 1998;279:585-92.

42 Fried LP, Tangen CM, Walston J, Newman AB, Hirsch C, Gottdiener J, et al. Frailty in older adults: evidence for a phenotype. / Gerontol $A$ Biol Sci Med Sci 2001;56:M146-56.

43 Guralnik JM, Simonsick EM, Ferrucci L, Glynn RJ, Berkman LF, Blazer DG, et al. A short physical performance battery assessing lower-extremity function-association with self-reported disability and prediction of mortality and nursing-home admission. J Gerontol 1994;49:M85-94.

44 Klein BE, Klein R, Knudtson MD, Lee KE. Frailty, morbidity and survival. Arch Gerontol Geriatr 2005;41:141-9.

45 Penninx BW, Ferrucci L, Leveille SG, Rantanen T, Pahor M, Guralnik JM. Lower extremity performance in nondisabled older persons as a predictor of subsequent hospitalization. J Gerontol $A$ Biol Sci Med Sci 2000;55:M691-7. 
46 Van den Beld AW, Visser TJ, Feelders RA, Grobbee DE, Lamberts SW. Thyroid hormone concentrations, disease, physical function, and mortality in elderly men. J Clin Endocrinol Metab 2005;90:6403-9.

47 DerSimonian R, Laird N. Meta-analysis in clinical trials. Control Clin Trials 1986;7:177-88.

48 Higgins JP, Thompson SG. Quantifying heterogeneity in a metaanalysis. Stat Med 2002;21:1539-58.

49 Higgins JP, Thompson SG, Deeks JJ, Altman DG. Measuring inconsistency in meta-analyses. BMJ 2003;327:557-60.

50 Thompson SG, Sharp SJ. Explaining heterogeneity in meta-analysis: a comparison of methods. Stat Med 1999;18:2693-708.

51 Higgins JP, Thompson SG. Controlling the risk of spurious findings from meta-regression. Stat Med 2004;23:1663-82.

52 Sterne JA, Gavaghan D, Egger M. Publication and related bias in meta-analysis: power of statistical tests and prevalence in the literature. J Clin Epidemiol 2000;53:1119-29.

53 Egger M, Davey Smith G, Schneider M, Minder C. Bias in metaanalysis detected by a simple, graphical test. BMJ 1997;315:629-34.

54 Begg CB, Mazumdar M. Operating characteristics of a rank correlation test for publication bias. Biometrics 1994;50:1088-101.

55 Walston J, Hadley EC, Ferrucci L, Guralnik JM, Newman AB, Studenski SA, et al. Research agenda for frailty in older adults: toward a better understanding of physiology and etiology: summary from the American Geriatrics Society/National Institute on Aging Research Conference on Frailty in Older Adults. J Am Geriatr Soc 2006;54:991-1001.

56 Kuh D, Bassey EJ, Butterworth S, Hardy R, Wadsworth MEJ. Grip strength, postural control, and functional leg power in a representative cohort of British men and women: associations with physical activity, health status, and socioeconomic conditions. J Gerontol Med Sci 2005;60A:224-31.

57 Kuh D, Hardy R, Butterworth S, Okell L, Richards M, Wadsworth MEJ, et al. Developmental origins of midlife physical performance: evidence from a British birth cohort. Am J Epidemiol 2006;164:110-21.

58 Kuh D, Hardy R, Butterworth S, Okell L, Wadsworth M, Cooper C, et al. Developmental origins of midlife grip strength: findings from a birth cohort study. J Gerontol Med Sci 2006;61:702-6.

59 Guralnik JM, Butterworth S, Wadsworth MEJ, Kuh D. Childhood socioeconomic status predicts physical functioning a half century later. J Gerontol Med Sci 2006;61:694-701.

60 Sayer AA, Syddall HE, Gilbody HJ, Dennison EM, Cooper C. Does sarcopenia originate in early life? Findings from the Hertfordshire cohort study. J Gerontol A Biol Sci Med Sci 2004;59:M930-4.

61 Galobardes B, Smith GD, Lynch JW. Systematic review of the influence of childhood socioeconomic circumstances on risk for cardiovascular disease in adulthood. Ann Epidemio 2006;16:91-104.

62 Turrell G, Lynch JW, Leite C, Raghunathan T, Kaplan GA. Socioeconomic disadvantage in childhood and across the life course and all-cause mortality and physical function in adulthood: evidence from the Alameda County Study. J Epidemiol Community Health 2007;61:723-30.

63 Higgins JP. Commentary: heterogeneity in meta-analysis should be expected and appropriately quantified. Int J Epidemiol 2008;37:1158-60.

64 Ioannidis JP, Patsopoulos NA, Rothstein HR. Reasons or excuses for avoiding meta-analysis in forest plots. BMJ 2008;336:1413-5.

65 Rucker G, Schwarzer G, Carpenter JR, Schumacher M. Undue reliance on I(2) in assessing heterogeneity may mislead. BMC Med Res Methodol 2008;8:79.

66 Guralnik JM, Branch LG, Cummings SR, Curb JD. Physical performance measures in aging research. J Gerontol Med SC 1989;44:M141-6.

Accepted: 16 June 2010 